ceasing to be. A careful perusal has disclosed nothing that can give a well-intentioned critic occasion to say "this is a happy idea-that is capitally put--this is something to help us." On the contrary, if this book were to be reviewed in detail, it would be necessary to write columns of complaint. One feature of novelty appears in the book in the form of full-page illustrations of apparatus and materials used in all the experiments. These pictures are reproduced from photographs, and show three tiers of apparatus arranged as if for sale. In many cases it is not easy for an experienced chemist to recognise the individual pieces, and in plate $\mathrm{xx}$. we reach a climax. It represents on the top shelf two tin canisters, a stoppered bottle, a Bunsen burner, a beaker, a tin dish, a blowpipe and another stoppered bottle. On the next shelf are three stoppered bottles, a hammer, four tin canisters, a small structure like a dog kennel, and a rack of twelve test-tubes. On the bottom shelf are two developing trays, a beaker, a stoppered bottle, a sugar basin, a stone gingerbeer bottle, a pocket handkerchief and apparently a bank-note or a shirt cuff. The plate bears the legend "The Metals." By the use of a lens one word of two of the labels can be deciphered.

A. S.

\section{SOLID GEOMETRY.}

The Elements of Euclid, BookXI. By R. Lachlan, Sc.D.

Pp. 51. (London: Edward Arnold, n.d.) Price Is.

$\mathrm{T} T$ is to be hoped that some of the scientific committees 1 which are now dealing with the improvement of mathematical teaching, and more especially with that of the teaching of elementary geometry, will, in the process of pruning Euclid, direct attention to this little-read Book xi. As in other books of the Elements, many of the propositions are of the trivial, or even ludicrous, character, while some of the definitions lack precision. For example, can prop. I-_" one part of a straight line cannot lie in a plane and another part without the plane"-be seriously regarded as necessary? Indeed, the proof assumes the thing which it seeks to prove: let $\mathrm{A} \mathrm{B} \mathrm{C}$ be the given straight line ; let a part of it, $\mathrm{A} \mathrm{B}$, lie in the plane, and a part, $\mathrm{B} \mathrm{C}$ (if possible), out of the plane ; produce A B in the plane to any point, D, \&c. To this several other instances might be added.

Then as regards definition, the descriptions of dihedral, trihedral and (generally) polyhedral angles leave something to be desired. Possibly some better term than angle can be found in such cases. We are told that "when two planes meet and are terminated at their line of intersection, they are said to form a dihedral angle"; "when several planes meet in a point, they are said to form a polyhedral angle." All that such planes visibly "form" is a certain figure; the "angle" which they form (as it is employed in subsequent mathematics) is, in reality, an area on a sphere of unit radius. It is true that Book xi. is not concerned with this precise quantitative definition of (so-called) solid angles-better called conical angles - but merely with certain plane, or face, angles connected with them; nevertheless, it may be desirable to give the student, who when he reaches Book xi. can scarcely be called a beginner, this quantitative notion.

$$
\text { No. I703, voL. } 66]
$$

In the small compass of this book there is little opportunity for anything strikingly original or novel. Dr. Lachlan finishes it with an appendix which contains a large number of propositions, examples, \&c., and this appendix will be found much more valuable than Book xi. itself.

A few criticisms of a minor character may not be out of place. We notice that in the enunciation of each proposition, Dr. Lachlan always uses the simple word "is" or "are" when the proposition states a fact which can be proved; thus, "if two planes intersect, their line of intersection is a straight line." The typical editor of a modern Euclid would say "their line of intersection shall be a straight line," employing a ridiculous compulsory form of expression. There is now the beginning of a revulsion against this style, which has been considered for some curious reason to be appropriate and essential to Euclid, but to no other subject of study or conversation. So far, Dr. Lachlan is in agreement with common sense; but why does he, when setting out on the proof of the proposition, re-state the fact with a "shall be"? Twice he forgot his rule-in prop. I, where "must be" is employed, and prop. 14, where the simple and sensible "are" of the formal enunciation remains "are" in the re-statement.

The proof of prop. 20 would avoid a tendency to mislead the student if it stated that the point $\mathrm{C}$ is first taken (arbitrarily), then E, and finally $\mathrm{B}$ and $\mathrm{D}$ by drawing any line, $\mathrm{E} \mathrm{B} \mathrm{D,} \mathrm{through} \mathrm{E}$.

In the third line of the proof of prop. 21 , the proof is rendered very much more clear by the insertion of the word "all" before the words "the $\angle \mathrm{s}$," the statement then being the very obvious one that if there are two sets of fifty plane triangles, the sum of all the angles in the first set is equal to the sum of all those in the second set.

Finally, the employment of the word "power" in the definition (p. 536) "the square on the distance between a point and the centre of a sphere less the square on the radius of the sphere is called the power of the point with respect to the sphere" does not seem justifiable or necessary, although it has been employed by a geometer of high repute. The word power is already employed in science for something quite different from the square of a tangent. Indeed, a student of electricity might be tempted to think that this geometrical ".power of points" is a mere pun on the well-known term used in connection with frictional machines. Everything must not be sacrificed to brevity; if new terms are wanted in science, they should be appropriate and expressive.

\section{BELGIAN BOTANICAL INVESTIGATIONS.}

Recueil de IInstitut Botanique (Université de Bruxelles).

Par L. Errera. Tome v. Pp. xii +357 . (Bruxelles :

Henri Lamertin, 1902.)

$\mathrm{I}$ this book there are brought together recent papers by botanists of the Royal Academy of Belgium, which have already been published in different journals during the last two years. Although this is the first volume to be published, it appears as vol. v., since the first four volumes will be given up to earlier papers. Thus 